DAEDALEAN ASSOCIATES, Incorporated

\title{
DETERMINATION OF THRESHOLD VELOCITIES \\ AND CORRELATION OF HIGH-FREQUENCY \\ ENDURANCE LIMITS FOR LMFBR \\ HEAT-EXCHANGER MATERIALS
}

BY

John Cavanaugh

February 1974

$$
\text { A.TOZ-r6. SF }
$$

\section{Atomics International Division \\ Rockwell International \\ 8900 DeSoto Avenue \\ Canogo Park, Calif. 91304}

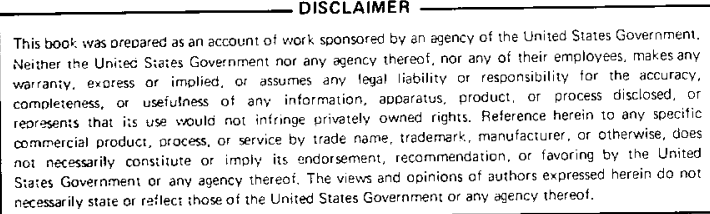




\section{DISCLAIMER}

This report was prepared as an account of work sponsored by an agency of the United States Government. Neither the United States Government nor any agency Thereof, nor any of their employees, makes any warranty, express or implied, or assumes any legal liability or responsibility for the accuracy, completeness, or usefulness of any information, apparatus, product, or process disclosed, or represents that its use would not infringe privately owned rights. Reference herein to any specific commercial product, process, or service by trade name, trademark, manufacturer, or otherwise does not necessarily constitute or imply its endorsement, recommendation, or favoring by the United States Government or any agency thereof. The views and opinions of authors expressed herein do not necessarily state or reflect those of the United States Government or any agency thereof. 


\section{DISCLAIMER}

Portions of this document may be illegible in electronic image products. Images are produced from the best available original document. 
DAEDALEAN ASSOCIATES, Incorporated

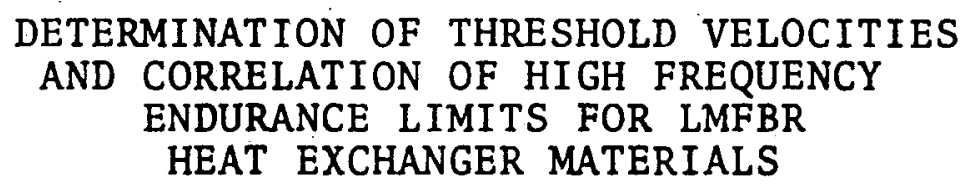

SUMMARY

Jet impact erosion tests and high frequency fatigue tests were conducted for $21 / 4 \mathrm{Cr}-1$ Mo steel. Utilizing the relationship between the velocity of impact and the number of impacts to produce visible erosion, the threshold velocities were determined as $220 \mathrm{fps}$ and $140 \mathrm{fps}$ at $10^{7}$ cycles and $10^{8}$ cycles respectively. The relationship between the high frequency fatigue strength and the number of cycles to failure was determined at room temperature up to a maximum of $10^{9}$ cycles. The high frequency endurance limit at room temperature was determined to be approximately $32,000 \mathrm{psi}$ for $10^{8}$ cycles. In addition, the ratio of high frequency fatigue strength to water hammer stress for erosion inception was also obtained as 2.75 .

\section{INTRODUCTION}

In order to evaluate the magnitude of the erosion problems encountered in LMFBR heat exchangers, the design engineer needs 
DAEDALEAN ASSOCIATES, Incorporated

for his design calculations basic experimental data correlating the threshold water hammer (impact) stress on the material and the high frequency endurance limit of the material. The program output for this experimental research study constitutes a material design chart relating the ratio between the high frequency endurance limit and the water hammer pressure of the material as a function of the number of cycles (impacts) at room temperature for $21 / 4 \mathrm{Cr}-1$ Mo steel.

\section{Experimental Facility and Techniques The Jet Impact Erosion Facility}

The jet impact erosion facility consists of a rotating disk driven by a variable speed motor capable of sustaining operation at $20,000 \mathrm{rpm}$. The rotating disk is capable of holding six specimens and rotates in the horizontal plane cutting two sets of $1 / 32$ inch diameter vertical jets as shown in Figure 1. The erosion is caused by the impact of the test specimens on the solid jet at controlled speeds.

\section{The High Frequency Fatigue Facility}

The high frequency fatigue facility, Figure 2 consists of a piezoelectric ultrasonic transducer and associated power supply which is used to vibrate the tuned specimen. The 
DAEDALENA ASSOCIATES, Incorporated

measuring instrumentation includes a high frequency power meter, . a transducer for signal pick up, an oscilloscope, and a frequency counter. The frequency and amplitude of oscillations are monitored by the transducer pick-up which is located on the vibrating transducer assembly.

\section{Determination of Threshold Velocities}

Six test specimens were attached at three radial locations in the rotating disk described previously. This enabled the observation of two specimens at a preselected test velocity ensuring the reproducibility and reliability of the experimental observation. The test specimens were $3 / 8^{\prime \prime}$ inch in diameter. The observation of the specimens was adjusted to suit the test sequence in order to determine when denting or fracture occurred (i.e. frequent observations were taken at higher velocities where damage could be observed in a short time and the inverse for low velocities.). The observation consisted of removing a test specimen and of observing the surface exposed to liquid impact with $10 \mathrm{X}$ magnification under side lighting which would make the initial indentations "stand out" when illuminated at the proper angle to the surface. The time taken for the initiation of permanent plastic indentations on the surface of the test specimen through this procedure was recorded for different test 
DAEDALEAN ASSOCIATES, Incorporated

velocities. The number of impacts were calculated from the number of revolutions during that time multiplied by two the impacts per revolution. The relationship between the number of impacts to initiate erosion and the corresponding threshold velocity was plotted.

After the appearance of plastic dents on the specimen surface, this area of denting will continue to work harden as the test progresses, resulting in the fracture of small fragments of material from the surface.

\section{Determination of High Frequency Endurance Limit}

The underlying principle of the high frequency fatigue technique is the creation of longitudinal vibrations in a fatigue specimen designed to produce maximum uniaxial alternating strains at the nodal point at resonant frequency. These strains are further amplified by means of a well designed test specimen. The test specimen as shown in Figure 3 was designed by. Thiruvengadam and is tuned for $20 \mathrm{KHz}$.

The maximum strains at the node of the fatigue specimen can be calculated from the following formula:

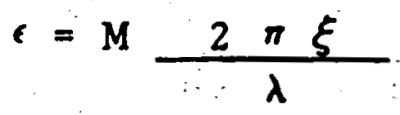


DAEDALEAN ASSOCIATES, Incorporated

.where $\epsilon=$ the strain amplitude at the node

$\xi=$ the displacement amplitude at the anti-node

$\lambda=$ the wave length in the material and

$M=$ Magnification Factor

The stress can be obtained by multiplying the strain with the modulus of elasticity. The frequency was accurately measured with a frequency counter and the time to failure was noted with the number of cycles to failure computed from the frequency.

\section{RESULTS AND ANALYSIS}

Correlation of Water Hammer Stresses with High Frequency Endurance Limits

Figure 4 shows the relationship between the velocity of impact and the number of impacts after which indentations were observed on the test material.

When a cylindrical column of liquid impinges on the surface of a material, the maximum stress developed at the point of contact by the impact ("water hammer" stress) is derived as:

$$
o_{1}=\frac{\rho_{l} C_{l} V_{1}}{1+\frac{\rho_{i} C_{l}}{\rho_{m} C_{m}}}
$$


DAEDALEAN ASSOCIATES, Incorporated

where

$V_{x}=$ impact velocity
$P_{l}=$ density of liquid
$P_{m}=$ density of material
and $\quad C_{l}=$ velocity of sound in liquid
$\quad C_{m}=$ velocity of sound in the material.

For this investigation in which water was the test liquid and a common metal was the test material, the ratio is small compared to unity. Then the water hammer stress becomes:

$$
\sigma_{x}=\rho_{l} C_{l} V_{x}
$$

The values of $P_{l} C_{l} V_{x}$ were calculated for the data shown in Figure 4. The values of $P_{l}$ and $c_{l}$ for water were obtained from published literature.

The ratio of high frequency fatigue strength to the water hammer stress for erosion inception is shown in Figure 5 for the test materiai. 


\section{CONCLUSIONS AND RECOMMENDATIONS}

Utilizing the relationship between the velocity of impact and the number of impacts to produce visible erosion, . the threshold impact velocities were determined as $220 \mathrm{fps}$ and $140 \mathrm{fps}$ at $10^{7}$ cycles and $10^{8}$ cycles respectively. The relationship between the high frequency fatigue strength and the number of cycles to failure was determined at room temperature up to a maximum of $10^{9}$ cycles. The high frequency endurance limit at room temperature was determined to be approximately 32,000 psi for $10^{8}$ cycles. In addition, the ratio of high frequency fatigue strength to the water hammer stress for erosion inception was determined as 2.75 .

As evidenced by the formation of oxide films, it appears that the $21 / 4 \mathrm{Cr}-1$ Mo steel could be considered corrosion prone. It would therefore be our recommendation that supplemental tests be conducted with pre-oxidized specimens. In conjunction with the temperatures associated with the LMFBR, we also recommend generation of high frequency fatigue data at high temperatures for correlation to threshold impact speeds of high temperature operation. 
DAEDALEAN ASSOCIATES, Incorporated

\section{REFERENCE}

1. A. Thiruvengadam, S.L. Rudy, and M. Gunasekaran "Experimental and Analytical Investigations on Multiple Liquid Impact Erosion" NASA CR-1638, National Aeronautics and Space Administration, Washington, D.C., September 1970. 


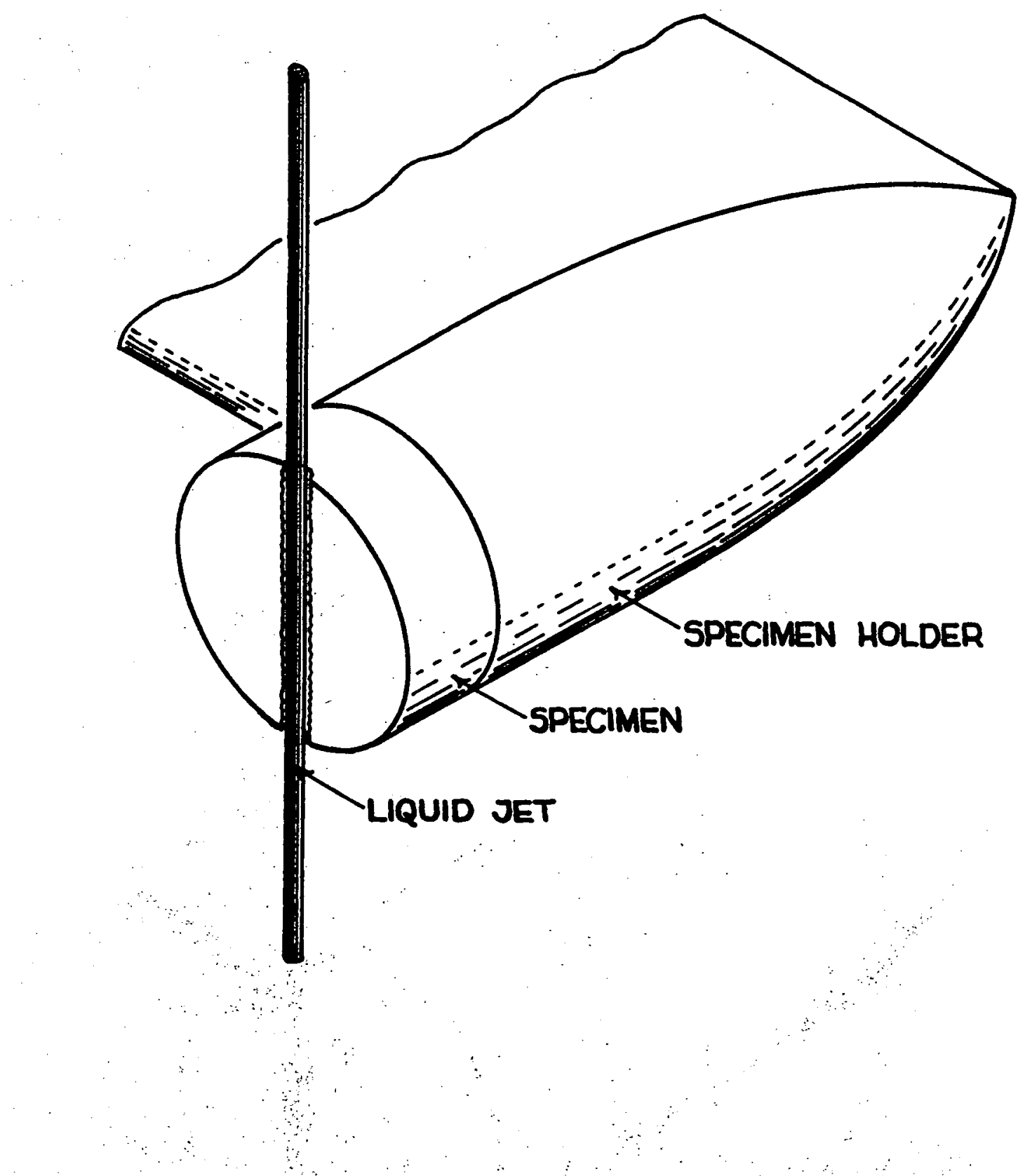

FIGURE 1 - TEST SPECIMEN IMPACT ON LUQUID JET. 
DAEDALEAN ASSOCIATES, INCORPORATED

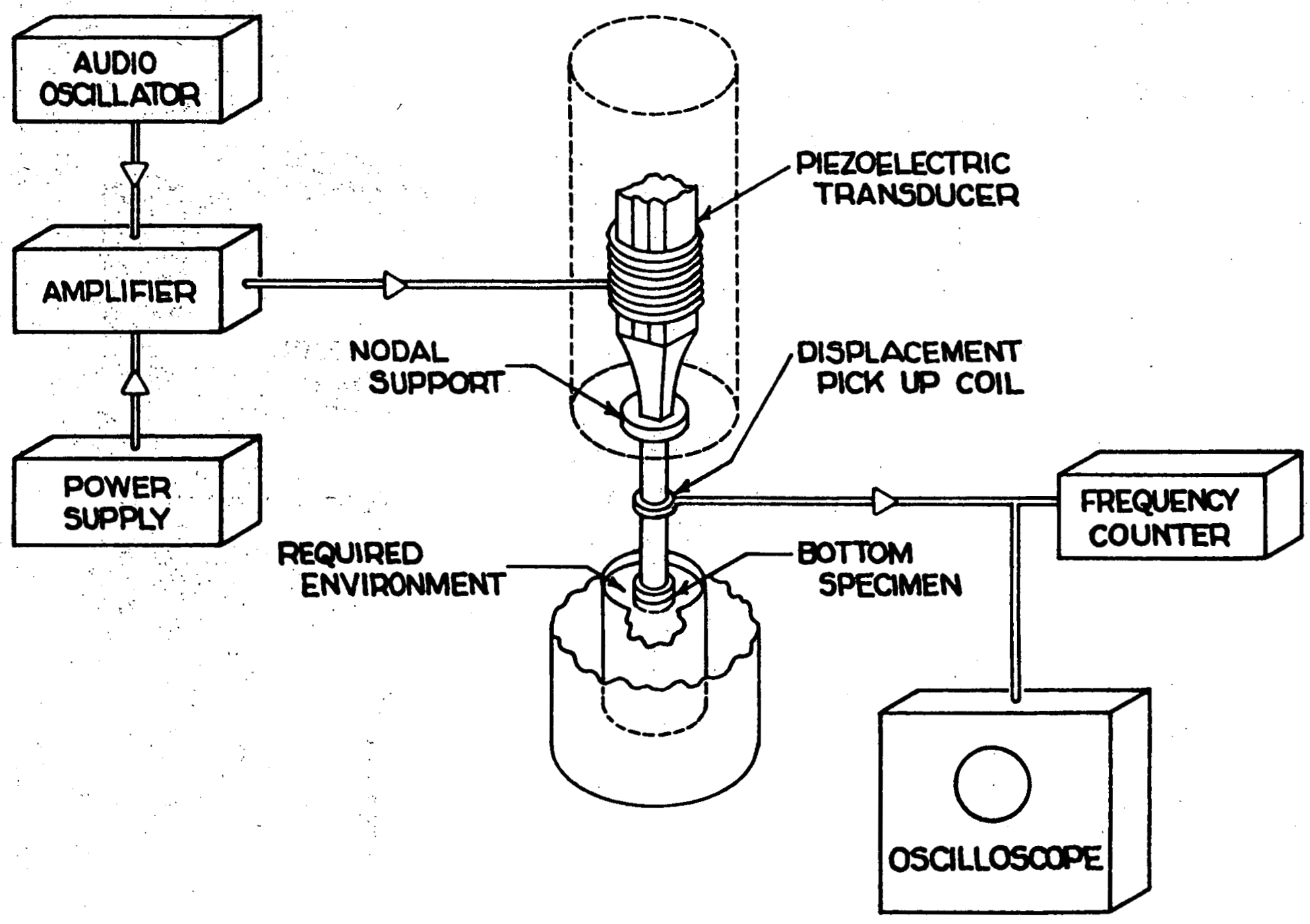

FIGURE 2 - BLOCK DIAGRAM OF THE hIGH FREQUENCY fatigue testing appapatus. 
DAEDALEAN ASSOCIATES, INCORPORATED

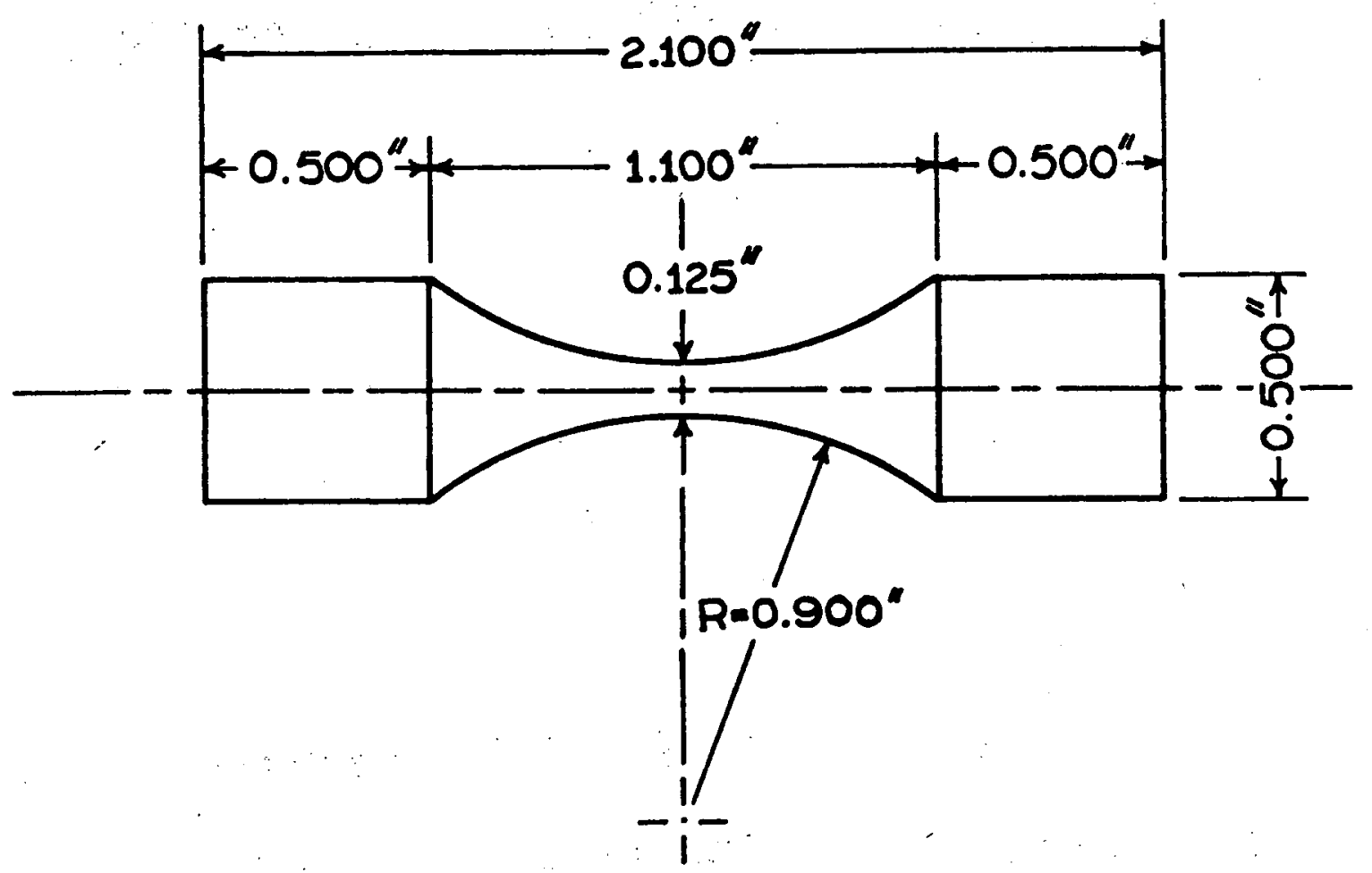

FIGURE 3 - HIGH FREQUENCY FATIGUE SPECIMEN FOR 21/4CR-1MO STEEL. 


\section{DAEDALEAN ASSOCIATES, INGORPORATEO}

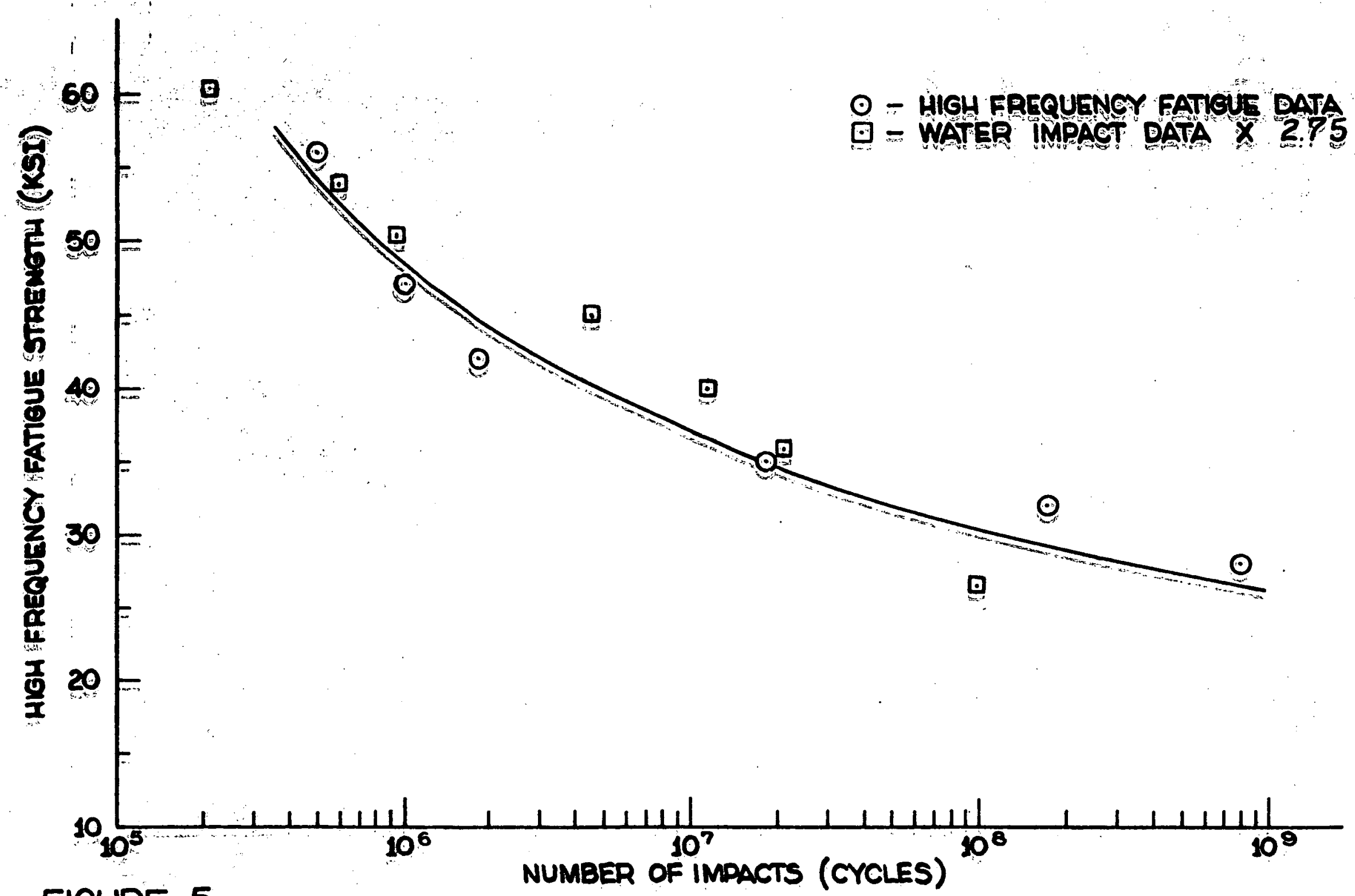

FIGURE 5 - CORRELATION OF HIGH FREQUENOY FATIGUE STRENGTH 